but by the localized inflammation due to the irritant action of the granules of oxide of silver which are deposited in the dermal and subdermal tissue, thus hastening cell death and producing ulceration, as any other localized inflammation may do.

\section{FOUR CASES OF EYE DISEASE FOLLLOWING BRAIN DISEASE,}

BY HENRY G. CORNWELl, M.D., COLUMBUS, O., PROFESSOR OF OPHTHALMOLOGY AND OTOLOGY IN STARLING MEDICAL COLLEGE. [Read in the Section on Ophthalmology, Otology and Laryngology,

HEMIANOPSIA HOMONYMA IDEXTRALIS AFTER APOPLEXY.

Mrs. S., aged 65, an intelligent lady of Columbus, was sent to me by Dr. Fullerton, her family physician, February $\mathbf{~}$, $\mathbf{1} 883$, for advice concerning a defect of vision, which had made its appearance three months before. The previous history of her case is as follows :

'Two years before she had an attack of apoplexy, was comatose for twelve hours, and remained hæmiphlegic on the left side for nine months, improving gradually until she entirely recovered without sequellæ from her illness, and enjoyed good health for fourteen months. One month before I saw her she was about to call on some of her friends, and as she ascended the steps her vision became suddenly obscured, and on entering the house she observed that she could only see the left half of objects toward which her eyes were directed. Her mental faculties remained clear, and she was absolutely free from all other symptoms of intra-cranial disease. Her hemianopsia (it being right-sided) prevented her from reading, a thing which distressed her exceedingly. On examination I found central vision $\underset{20}{\mathrm{xx}}$, or normal. Entire absence of all visual impressions, except for light over the right half of the visual field, the line of demarcation being sharply defined and extending to the macula lutea. Visual and color sense normal over the left half. Ophthalmoscopic evidence negative. Her condition remains, after three months, unchanged.

My view of the pathological condition in this case is, that at the time of the sudden appearance of the hemianopsia the patient had a second hæmorrhage of slight extent, doubtless into the occipital lobe of the left hemisphere, the injury to the brain substance being only sufficient to produce the visual defect.

A CASE OF MONOCULAR OPTIC NEURITIS, FROM BRAIN DISEASE.

J. H., æt. 26, of Mt. Vernon, O., a machinist, single, visited me October $20, \mathbf{I} 882$, on account of a failure of vision in the right eye of three weeks duration. From his history he had evidently contracted syphilis five years before. On examination, the vision of the right eye was reduced so that he could see only to count fingers at five feet. He had also paralysis of the third nerve on the same side, producing ptosis, a dilated and fixed pupil, and divergent strabismus. The sense of smell was wholly gone on that side. The pacient also complained of severe frontal headache, and became at times very giddy and faint. The ophthalmoscope revealed a violent monocular right-sided optic neuritis, the swelling amounting to three dioptrics. Left eye vision and ophthalmoscopic appearances normal. The bichloride of mercury and iodide of potassium were given in large doses for some weeks, and improvement followed so far that some movement of the globe inward could be obtained. Atrophy of the optic nerve succeeded the neuritis, and vision was reduced to perception of light. No further improvement followed treatment.

The eye-condition in this case evidently was due to an intra-cranial gummous formation at the sphenoidal fissure and optic foramen on the right side.

PARALYSIS OF SIX OF 'THE CRANIAL NERVES FROM BASILAR MENINGITIS.

J. D., æt. 37 , a dentist of Columbus, visited me May I8, r883. During the war, he received a flesh wound in the right forearm, and was left uncared for in a vacant house for 48 hours; the nights were very cold. Following this he had swamp-fever, and subsequently became seriously ill with some form of brain disease. His recovery was complete, except so far as his eyes were concerned, they having remained unchanged since his convalescence, except that his visual power is monthly decreasing.

Status preséns:-Patient in an advanced stage of pulmonary consumption; no history of syphilis. Absolute immobility of both eyeballs, and double ptosis, from paralysis of the third, fourth and sixth pairs of cranial nerves. Paralysis of the facial on both sides; some impairment of cutaneous sensibility. over the face. Vision, ability to count fingers at five feet. The optic nerves in an advanced stage of secondary atrophy; the irides and ciliary muscles not paralyzed. He has never had any form of general paralysis, and his intelligence has not been impaired since his illness.

This case exhibits paralysis of six pairs of the cranial nerves. I regard the condition as having been due to a basilar meningitis which succeeded the intermittent fever.

A CASE OF CHOKED DISC ASSOCIATED WITH A TUBERCULAR TUMOR IN THE CEREBELLUM.

On the first of April, I 882, I was invited by Dr. Buckner, of Youngstown, O., to make an ophthalmoscopic examination in a case of brain disease, the previous history of which is as follows:

The patient, H. W., æt. 26, a locomotive engineer, had suffered for some weeks with intense frontal headache and lancinating pains shooting through the head from the occiput to the vertex. He had frequent attacks of giddiness and faintness, and on several occasions had convulsions after running. He had also become totally deaf on the left side. His vision was ${ }_{20}^{\mathrm{xv}}$, both eyes. No marked change in the visual field. Ophthalmoscope revealed choked disc; the swelling of the heads of the nerves measured five dioptrics. Rapping on the head did not give rise to pain. The tuning-fork was not heard on the left side. Brain tumor was diagnosed, and unfavorable prognosis given. No evidence of syphilis 
was obtained. Bichloride of mercury and iodide of potassium were prescribed.

I saw him a month later, and he had become wholly blind, and had had frequent convulsions in bed. During the next month his convulsive attacks a!peared daily, and he died comatose.

At the autopsy, in the left lobe of the cerebellum an abscess was found, containing about a teaspoonful of pus, and close to it a tumor the size of a marble, in the center of which was a calcareous deposit the size of a hemp-seed. The tumor was on examination found to be of the tubercular variety.

\section{SYMPTOMATOLOGY IN INFANTS.}

BY WILLIAM B. ATKINSON, M.D., LFCTURFR ON DISEASFS OF CHILDREN, AT JEFFERSON MEDICAI. COLLEGE, PHILADELPHIA.

By many persons, the study of disease in infants is regarded as peculiarly difficult, because of the absence of speech by which to indicate the presence and location of certain symptoms. The late Prof. C. D. Meigs, on the contrary, was wont to felicitate himself on this as an advantage. He would say, "An infant never tells a lie." It cannot imitate the young lady who assures the doctor that she is dying, or suffering unspeakable torments, when the next hour she is ready to whirl till daylight in the dance, or fill her stomach with a melange as curious as it is hurtful.

In the investigation of all forms of disease, whether in children or in adults, we are generally too apt to jump at a conclusion, and make a diagnosis which would often be different were it prepared with less haste, and with the aid of other factors. Careful, guarded observation should ever be the rule. The whole ground should be accurately surveyed; each symptom, each point compared, and the result will prove more satisfactory than is so frequently the case where, after a few hurried questions addressed to a stupid or careless nurse, and an equally careless examination of the infant, the physician supposes what is wrong, and writes a prescription which may be harmless; often is useless. It would be better to leave the child to nature, and give a placebo to satisfy and occupy the nurse, who will be sure to administer some of her own foolish mixtures if not otherwise employed.

At the outset, the most important matter to the physician is a thorough knowledge of the infant as a healthy being, that he may have a means of comparison by which to judge as to the presence or absence of disease. It is seldom, however, that these points are considered, and more rarely are they studied.

In this connection, I would refer to my lecture entitled " "The Conditions of Life in a Healthy Infant."

Additional force is given to these remarks by my observing, on a recent occasion, the great want of knowledge in the profession as to the commonest points in child-life, and a learned authority gives a striking example of the same, where, at a criminal trial, the experts summoned could only give the most vague and general ideas as to the quantity of food 1equired for a healthy child at a given age.
Starting, then, with a well-grounded knowledge of the child as it should be in health, we make a careful examination of the little one at every point. Its history and its surroundings must be equally inquired into, that we may thus be enabled to eliminate any points tending to confuse in grouping the results of these inquiries.

In such an examination, we are largely, if not wholly dependent upon the objective symptoms.

We must learn from the attitudes; the movements ; the cries; the skin ; as well as the pulse, respiration and temperature. In fact, the last three are least to be depended upon.

In health, the attitude of a young child should be a natural, easy one, with no appearance of strain in any of its motions. Here, however, is room for error, unless we possess a knowledge of the special case which we are investigating, as children are often observed to assume in health an attitude simulating that of disease. Hence, a peculiar or apparently unnatural position should not cause alarm unless associated with other positive symptoms. We have frequently seen infants sleeping with the head drawn far back, similar to the position of one suffering from cerebrospinal fever. When it is observed that the movement of any part causes pain or uneasiness, that point should demand the closest investigation, and at the same time a search should be made as to the occurrence of any causes likely to have produced such a result.

Perhaps the first point which attracts the attention is the face of the infant. While we cannot fully agree with some authors that there is such a close relation between the expression of the countenance and the seat of disease, yet we know that much is to be learned here.

Pain is at once shown by the face.

Corrugation of the brow, twitching of the corners of the mouth, tremulous movements of the eye-lids, are generally prodromes of convulsions, and when associated with other symptoms should lead to the belief in the presence or cerebral trouble.

Pallor of the countenance almost invariably is present in intestinal diseases, and usually accompanied by a fretful, peevish look. This pallor, with emaciation of the features, is seen in all diarrhceal affections. When the exhaustion is great, as in cholera infantum, these symptoms are present to a marked extent, as seen in those sudden attacks where, within twenty-four hours or even less, the infant resembles a little old person, and is so altered that those around fail to recognize a familiar feature. Here we have the hollow cheek, the sunken eye with half-closed lid, the waxy, cadaverous look, a dark circle surrounding the mouth, deep blue circular lines beneath the eyes, the pinched nose, the mouth half open, disclosing the tongue, which lies parched in its cavity, the cold and feeble breath, all witnessing that great exhaustion preceding dissolution.

When the face is flushed, hot, swollen, we find acute brain disease. When the face assumes a dusky hue there is from some cause imperfect æration of the blood, as in congestion or other lung trouble. In cases of inflamed lung the hue is brighter, and asso- 